\title{
Impact of virtual training on safety and productivity in the mining industry
}

\author{
$\underline{\text { Shiva Pedram }}^{1}$, Pascal Perez ${ }^{1}$, Bruce Dowsett $^{2}$ \\ ${ }^{1}$ SMART Infrastructure Facility, University of Wollongong, NSW \\ ${ }^{2}$ Coal Services Pty Ltd, Argenton, NSW
}

\begin{abstract}
Best practice in the mining industry includes extensive initial and professional training for staff involved in field operations. While changes in mining technology and operations accelerate to improve productivity, health and safety standards have to be continuously evaluated and improved, putting more pressure on training deliveries. Borrowing from Defence and Airspace industries, training in the mining industry is increasingly relying on immersive virtual reality to simulate complex operations and procedures in potentially dangerous environments. Coal Services Pty Ltd is at the forefront of modern training facilities in Australia.

This paper presents a qualitative and quantitative research framework designed to analyse the impact of past and current training sessions on staff's ability to better perform their tasks, overall safety standards and mine productivity. It is relatively difficult to benchmark training techniques or programs in the mining industry as the very nature of the industry prevents from experimental comparisons with a control group. Hence, we have chosen to use diachronic methods to evaluate the effective impact of IVR-based training on worker's competences. In particular, our interviews with managers and access to relevant industry records will help us to identify two periods: before and after the introduction of IVR-based training. Another more qualitative approach will consist in interviewing personnel who have undertaken during their career at least two types of training programs, including IVR-based ones. The framework uses interviews with trainees, trainers and managers, alongside session recordings, to qualitatively evaluate levels of knowledge transfer and aptitudes to perform in a real environment. Then, a cost-benefit analysis is to be used to evaluate the added-value of virtual reality-based on technological and operational costs weighed against overall productivity of the mine being negatively affected by any safety issue.
\end{abstract}

Keywords: $\quad$ Simulation, training, virtual reality, mining industry, safety 


\section{INTRODUCTION}

There is an abundant literature on research dedicated to Interactive Virtual Reality (IVR) environments (Bell 1991; Rickel and Johnson 1998; Furlong, Vance et al. 1999; Burdea and Coiffet 2003; Fox, Arena et al. 2009; Jou and Wang 2012), IVR-based teaching and training programmes (Salzman, Dede et al. 1999; Moreno and Mayer 2002; Moreno and Mayer 2007) or their application to different industries (Orlansky and String 1977; Bakken, Gould et al. 1992; Filigenzi, Orr et al. 2000; Deaton, Barba et al. 2005; van Wyk and de Villiers 2009; Rai and Wong 2010; Schmitt, Agarwal et al. 2012). Literature investigating and evaluating the impact of IVR-based training programs on safety and productivity records is far less abundant. This is particularly relevant for those industries where organisational health and safety issues are of the prime importance such as the mining industry. In order to evaluate the impact of IVR on training delivery, improvement to safety records and overall impact on productivity it is necessary to access and analyse data from past and current training programs, along with feedback from trainees, trainers and various managerial levels. This data needs to be processed within a formal analytical framework that can incorporate qualitative and quantitative data, micro-scale (training session) to macro-scale (corporate) levels.

\subsection{Mine and Safety}

The mining industry faces both needs for high performance productivity and for drastic safety standards in the most hazardous working environments. Henceforth, it seems natural that the American Mine Safety and Health Administration (MSHA) asked the National Institute for Occupational Safety and Health (NIOSH) to explore and implement the use of IVR technology to develop training programs for open-cut or underground mining about hazard recognition and evacuation ways and processes (Filigenzi, Orr et al. 2000). Likewise, South Africa started using IVR-based training programs in order to improve alarming workplace safety statistics. The South African Mine Health and Safety Authority (MHSA) started developing training environments as realistic and interactive as possible. Different technologies like joysticks, data gloves or head-mounted displays were used to enhance trainee's immersion (Kizil 2003). Open-cut or underground mining simulators provide safe, replicable and cost-effective environments for miners to be trained and for engineers and managers to test different assumptions, strategies and scenario outcomes. Henceforth, IVRbased training has the potential not only to improve workplace safety conditions, but also to contribute to a more effective management, more sustainable production and, finally, more profitable industry (van Wyk and de Villiers 2009). In Australia, the NSW Mine Safety Advisory Council (MSAC) focuses on industry culture change through the implementation of mine safety plans and the improvement of technical and non-technical skills at all levels of management. Lost-time injury, a usual metric used to assess progress, is defined as an incidence that causes a fatality, permanent disability or injury resulting in time loss over one shift or more,(Nathan Wales October 2012). Table 1 presents the evolution of lost-time injury in NSW over the last decade.

\begin{tabular}{|l|c|c|c|c|}
\hline & Coal & Metalliferous & Extractive & $\begin{array}{c}\text { All NSW } \\
\text { mining }\end{array}$ \\
\hline $2000-2001$ & 33.00 & 17.62 & 6.27 & 23.80 \\
\hline $2001-2002$ & 27.00 & 9.63 & 20.45 & 23.12 \\
\hline $2002-2003$ & 23.00 & 9.68 & 26.54 & 20.52 \\
\hline $2003-2004$ & 22.00 & 6.55 & 30.18 & 17.57 \\
\hline $2004-2005$ & 18.00 & 4.28 & 9.00 & 13.85 \\
\hline $2005-2006$ & 15.20 & 4.55 & 8.30 & 12.46 \\
\hline $2006-2007$ & 16.30 & 5.99 & 6.98 & 13.19 \\
\hline $2007-2008$ & 8.27 & 4.45 & 5.67 & 7.26 \\
\hline $2008-2009$ & 8.19 & 3.35 & 12.11 & 7.57 \\
\hline $2009-2010$ & 7.13 & 4.36 & 11.10 & 6.88 \\
\hline $2010-2011$ & 5.83 & 2.54 & 10.23 & 5.46 \\
\hline
\end{tabular}

Table 1. The number of lost-time injuries per million employee hours worked in the NSW minerals industry (2000 to 2011) 
The main objective of this study is to analyse and evaluate the impact of IVR-based training on mining safety, management and planning processes. In other words, we aim to evaluate the quality of the 'training transfer'.

\subsection{Conceptual Framework}

VanWyk and Villiers (2009) define IVR-based training environments as "real-time computer simulations of the real world, in which visual realism, object behaviour and user interaction are essential elements". The use of IVR-based training environments assumes that Human-Machine interaction stimulates learning processes through better experiencing and improved memorization, leading to a more effective transfer of the learning outcomes into workplace environments. As stated by Meadows (2001): "When I hear, I forget; when I see, I remember; when I do, I understand". Fulton and colleagues (2011) argue that interactive models like flight simulators are designed to improve trainee's understanding of the consequences of decisional queues under limited resource availability (material, time or energy) and uncertain or hazardous conditions (unintended consequences). The more realistic the experience is, the stronger the learning process. In situations where real life training opportunities are limited, hazardous or impossible, like emergency responses, virtual reality simulators offer the opportunity to emulate many wide-ranging experiments (Seymour, Gallagher et al. 2002).

A crucial condition for IVR technology to deliver satisfying training transfer is its ability to reproduce faithfully not only the physical environment but also functional features of the simulated operations. In the case of flight simulators, Hays et al. (1992) demonstrated that the quality of training transfer is highly correlated to the level of fidelity of the simulated environment to the real world. Orlansky and String (1977) argue that the effectiveness of IVR-based training is influenced by (1) the type of simulator in use, (2) the level of experience of participants and (3) the quality of scenario design and delivery.

A successful mining training program, being IVR-based or not, should result in the creation of a safer workplace ('the mine') and a more competent workforce ('the miners'), contributing to a more effective management of field operations. In turn, improved management will have significant and durable impact upon higher industry objectives like sustainable production, corporate profitability and social responsibility (Figure 1).

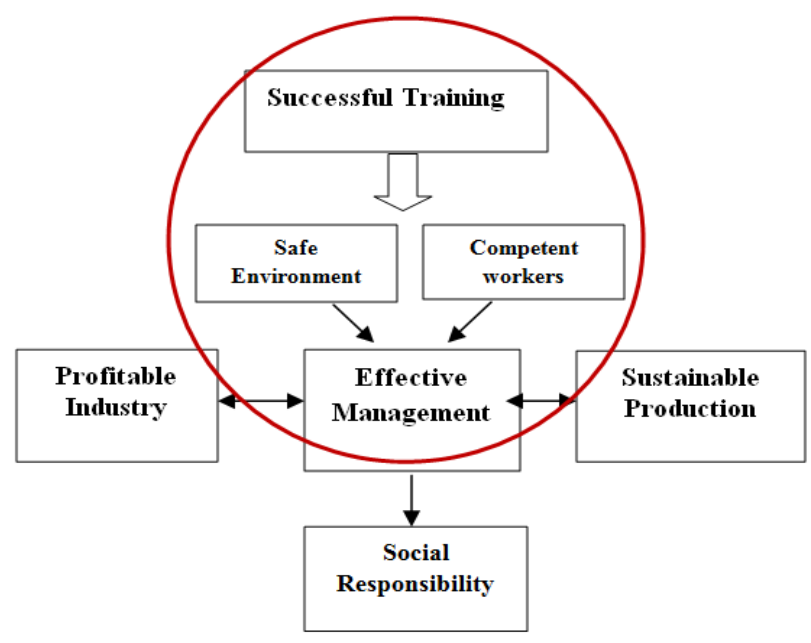

Figure 1: Potential impact of IVR-based training on various aspects of mining operations

\section{A more competent workforce}

Most of the time, incidents result from human errors or uncontrolled situations. In a workplace context, a human error is defined as an action, intentional or not, having a negative impact on safety or productivity. This definition covers a large range of circumstances like tripping over, slipping, bending a rule, violating a procedure or having a lapse of concentration (Figure 2). 


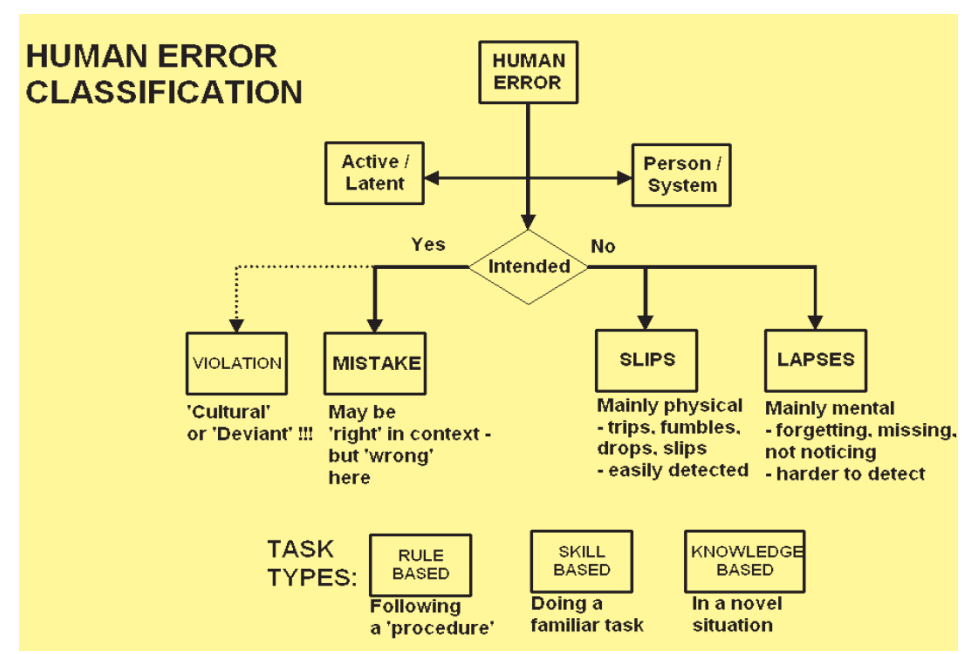

Figure 2: Human Error Classification (source: Mine Safety tools , 2013)

The assumption behind the development of IVR-based training for the mining industry is that it will produce more aware and better prepared workers, at a competitive cost, compared with more traditional approaches. In a context where real world training is either too dangerous or too demanding on production, investing in virtual reality technology seems to be a reasonable choice (Kral 2002). Drawing from the flight simulator paradigm (Orlansky and String 1977), mining simulators are designed to accelerate a worker's learning curve in a realistic but safe environment through repeated experiments. Causal queues and repetitions are meant to stimulate individual experiences and to enrich corresponding mental models (Jou and Wang 2012). Ultimately, this learning in context should limit the number of human errors to a tolerable level as skill sets dramatically improve (Deaton et al., 2005).

\section{A safer workplace}

Salzman et al. (1999) argue that IVR-based training can support a second-order learning process through which designers, trainers and managers gain insight into interactions between workers and their environment. Analysing training scenarios, trainee's performance and feedback after the session could lead to better workplace conditions by modifying features of the current environment. Henceforth, mining simulators could become platforms for testing and implementing new ideas developed by engineers or managers with immediate (and safe) response from the workforce. To our knowledge, the use of IVR-based simulations to improve the working environment has not received enough attention to date.

\section{RESEARCH METHOD}

Our case study focuses on a training facility located in Wonoona (NSW) operated by Coal Services Pty Ltd, an Australian service provider. The objective is to evaluate the impact of IVR-based training programs on worker's competences, safety records and mine productivity. We have chosen to use diachronic methods to evaluate the effective impact of IVR-based training on worker's competences. In particular, our interviews with managers and access to relevant industry records will help us to identify two periods: before and after the introduction of IVR-based training. Interviews with trainees, trainers and managers alongside direct recording of training sessions will constitute our primary data. Secondary data will include records of previous sessions and industry assessment documents. Qualitative and quantitative analyses will be performed to evaluate the level of knowledge transfer and aptitudes to perform in a real environment. Then, a cost-benefit analysis will be used to evaluate the added-value of virtual reality-based on technological and operational costs weighed against overall productivity of the mine being negatively affected by any safety issue.

\subsection{Qualitative Analysis}

Assessing the quality of a training transfer involves three components: 1) Inputs including trainees 2) Outputs including learning and performance and 3) Training conditions including the environment. According to 
Salzman et al.(1999), there is a strong relationship between IVR features, individual characteristics and the IVR-based learning experience. In order to estimate the strength of this relationship across various groups of trainees and training scenarios, we will gather evidence at three stages:

\section{Before Training}

The focus will be on trainees' characteristics and their competency and knowledge level prior to attending the training sessions. The tools to collect this primary data will include individual questionnaires, interviews with managers and performance sheets. Whenever applicable, we will also ask trainees to draw causal loops diagrams of hypothetical scenarios before attending the session.

\section{During Training}

Aside from the electronic recording of training sessions by the Facility, we will conduct direct observations of individual and collective response to stimuli at specific stop points. These observations will include body language, oral communication between trainees or collective organisation during an exercise. The aim is to evaluate the learning experience.

\section{After Training}

At the end of a session, individual questionnaires and interviews will be used to record feedback from trainees and trainers. This material will be used to analyse individual responses to an IVR environment and to evaluate the quality of the training transfer in terms of competency. We will also attend debriefing sessions between trainees and trainers. Whenever applicable trainees will be asked to create a second causal loop of hypothetical scenarios in order to compare them with the initial ones.

\subsection{Quantitative Analysis (Cost-Benefit Analysis)}

Based on Yamnill and McLean (2001), training is pointless if it cannot be expressed through a performance measurement. Training should focus on performance and not only on learning. Whenever training can demonstrate a subsequent gain in performance then the training transfer is positive. Conversely in the absence of any gain in performance, the training transfer is negative (Yamnill and McLean 2001). Wehrmann et al. (2003) argue that a key point to assess the benefits of a training program is to evaluate its impact directly onto workplace performance. In this case, we propose to adapt the approach proposed by Micheli (1972) to measure the quality of training transfer for flight simulators. This approach includes two indicators: (1) the Performance Enhancement Measurement (PEM) and (2) the Effectiveness for Training Purposes (EfTP).

\section{Performance Enhancement Measurement}

PEM represents the amount of time saved to finish a task due to the IVR-based training sessions. It can also represent the enhancement in performance of employees after attending the training sessions. In this equation:

$\mathrm{Y}_{\mathrm{c}}$ : Indicates the number of hours required by the employee to finish a certain task without attending the training sessions in IVR environment.

$Y_{x}$ : indicates the number of hours required by the employee to finish the same task after attending the training sessions in IVR environments.

$$
\text { Percent Saving }=\frac{Y_{c}-Y_{x}}{Y_{c}} \times 100
$$

The greater the number the higher is the savings. Values for Yc and Yx will be derived from interviews with trainees and different levels of management.

\section{Effectiveness for Training Purposes}

The transfer effectiveness is a measure for evaluating the effectiveness of a training environment by quantifying the saving in time on the operational task as a function of the amount of time spends in the training environment. 
Pedram et al., Impact of Virtual Training on Safety and Productivity in the Mining Industry

$$
\text { Transfer effectiveness }=\frac{Y_{c}-Y_{x}}{X}
$$

Where in this equation:

Yc: Indicates the number of hours required by the employee to finish a certain task without attending the training sessions in IVR environment.

Yx: Indicates the number of hours required by the employee to finish the same task after attending the training sessions in IVR environments.

$\mathrm{X}$ : The training hours or sessions received by trainees in IVR.

The greater the number, the better the training transfer. In other words it indicates the amount of knowledge and skills trainee has been transferring from the virtual world to the real world.

Using PEM and EfTP indicators to assess potential benefits, we will use a costing model to conduct our costbenefit analysis. For example, Rai and Wong (2010) suggest that a flight simulator costs only $15 \%$ of using actual helicopters for training purposes. Drawing from their study, we have selected the following cost categories as our evaluation metrics:

- Costs associated with designing and developing a simulator

- Costs associated with operating an IVR-based training session

- Specific technology costs (Curve screen, Domes, 360 degree theatre)

\section{CONCLUSION}

This paper presented the research framework to quantitatively and qualitatively evaluate the effect of IVRbased training on training transfer in the mining industry. Two main components of effective management have been identified as a competent workforce and a safe workplace.

Our evaluation framework will be applied to an IVR-based training facility operated by Coal Services Pty Ltd in Wonoona (NSW, Australia).

Our methodology aims to collect a broad range of performance, behavioural, and attitudinal data to help with a qualitative and quantitative analysis of the impact of mining simulators on improving workforce's performance and workplace's safety records. This data, associated with cost estimates, will provide a reasonable basis for conducting a cost-benefit analysis that will provide the industry with an evidence-based outcome to examine its future investments in this technology.

\section{REFERENCES}

Bakken, B., J. Gould and D. Kim (1992). "Experimentation in learning organizations: A management flight simulator approach." European Journal of Operational Research 59(1): 167-182.

Bell, P. C. (1991). "Visual interactive modelling: The past, the present, and the prospects." European Journal of Operational Research 54(3): 274-286.

Burdea, G. and P. Coiffet (2003). "Virtual reality technology." Presence: Teleoperators \& Virtual Environments 12(6): 663-664.

Deaton, J. E., C. Barba, T. Santarelli, L. Rosenzweig, V. Souders, C. McCollum, J. Seip, B. W. Knerr and M. J. Singer (2005). "Virtual environment cultural training for operational readiness (VECTOR)." Virtual Reality 8(3): 156-167.

Filigenzi, M. T., T. J. Orr and T. M. Ruff (2000). "Virtual reality for mine safety training." Applied occupational and environmental hygiene 15(6): 465-469.

Fox, J., D. Arena and J. N. Bailenson (2009). "Virtual reality." Journal of Media Psychology: Theories, Methods, and Applications 21(3): 95-113.

Fulton, E. A., T. Jones, F. Boschetti, M. Sporcic, W. D. L. Mare, G. Symeb, P. Dzidic, R. Gortona, L. Little and G. Dambachera (2011). A multi-model approach to stakeholder engagement in complex environmental problems. International Congress on Modelling and Simulation (MODSIM 2011), Perth, WA. 
Pedram et al., Impact of Virtual Training on Safety and Productivity in the Mining Industry

Furlong, T. J., J. M. Vance and P. M. Larochelle (1999). "Spherical mechanism synthesis in virtual reality." TRANSACTIONS-AMERICAN SOCIETY OF MECHANICAL ENGINEERS JOURNAL OF MECHANICAL DESIGN 121(4): 515-520.

Hays, R. T., J. W. Jacobs, C. Prince and E. Salas (1992). "Flight simulator training effectiveness: A metaanalysis." Military Psychology 4(2): 63-74.

Jou, M. and J. Wang (2012). "Investigation of effects of virtual reality environments on learning performance of technical skills." Computers in Human Behavior.

Kizil, M. (2003). "Virtual reality applications in the Australian minerals industry." Application of Computers and Operations Research in the Minerals Industries, South African: 569-574.

Kral, S. (2002). "Improved training reduces worker injuries." Mining engineering 54(10): 23-26.

Meadows, D. L. (2001). "Tools for understanding the limits to growth: comparing a simulation and a game." Simulation \& Gaming 32(4): 522-536.

Micheli, G. S. (1972). Analysis of the transfer of training, substitution and fidelity of simulation of training equipment.

Mine safety tools. "Human Error Packet Tool." from http://www.resources.nsw.gov.au/_data/assets/pdf_file/0005/332915/Human-Error-PocketTool.pdf.

Moreno, R. and R. Mayer (2007). "Interactive multimodal learning environments." Educational Psychology Review 19(3): 309-326.

Moreno, R. and R. E. Mayer (2002). "Learning science in virtual reality multimedia environments: Role of methods and media." Journal of Educational Psychology 94(3): 598-610.

Nathan Wales. (October 2012). "Statistical Indicators 7/12." Retrieved June, 2013, from http://www.parliament.nsw.gov.au/prod/parlment/publications.nsf/key/MininginNSW\%28October2 012\%29/\$File/Mining+in+NSW+Statistical+Indicators+No+7+2012.pdf.

Orlansky, J. and J. String (1977). Cost-Effectiveness of Flight Simulators for Military Training. Volume 1. Use and Effectiveness of Flight Simulators, DTIC Document.

Rai, S. and K. Wong (2010). The use of interactive simulations to affect driving behaviour.

Rickel, J. and W. L. Johnson (1998). STEVE (video session): a pedagogical agent for virtual reality. Proceedings of the second international conference on Autonomous agents, ACM.

Salzman, M. C., C. Dede, R. B. Loftin and J. Chen (1999). "A Model for Understanding How Virtual Reality Aids Complex Conceptual Learning." Presence: Teleoperators \& Virtual Environments 8(3): 293316.

Schmitt, P. J., N. Agarwal and C. J. Prestigiacomo (2012). "From planes to brains: Parallels between military development of virtual reality environments and virtual neurological surgery." World Neurosurgery 78(3-4): 214-219.

Seymour, N. E., A. G. Gallagher, S. A. Roman, M. K. O'Brien, V. K. Bansal, D. K. Andersen and R. M. Satava (2002). "Virtual reality training improves operating room performance: results of a randomized, double-blinded study." Annals of surgery 236(4): 458.

van Wyk, E. and R. de Villiers (2009). Virtual reality training applications for the mining industry. Proceedings of the 6th international conference on computer graphics, virtual reality, visualisation and interaction in Africa, ACM.

Wehrmann, K. C., H. Shin and J. Poertner (2003). "Transfer of Training." Journal of Health \& Social Policy 15(3-4): 23-37.

Yamnill, S. and G. N. McLean (2001). "Theories supporting transfer of training." Human Resource Development Quarterly 12(2): 195-208. 